\title{
A summer school where master students learn the skills needed to work in an accredited analytical laboratory
}

\author{
Philip D. P. Taylor ${ }^{1}$ - Danuta Baralkiewicz ${ }^{2}$ - Ricardo Bettencourt da Silva ${ }^{3}$. \\ Darinka Brodnjak Vončina ${ }^{4}$ - Ewa Bulska ${ }^{5}$ - Maria Filomena Camoes ${ }^{3}$ • \\ Ryszard Dobrowolski $^{7} \cdot$ Marc Elskens $^{8} \cdot$ Ivo Leito $^{9}$ - Nineta H. Majcen ${ }^{10}$. \\ Petko Mandjukov ${ }^{11} \cdot$ Josephine McCourt $^{1} \cdot$ Jérôme Randon $^{6}$ • Paavo Perämäki ${ }^{12}$
}

Published online: 19 July 2015

(C) Springer-Verlag Berlin Heidelberg 2015

\section{Introduction}

Analytical and bio-analytical measurements play a crucial role in science and society at large and many students are taught a basic understanding and practical skills in the curricula they follow. Today, when important decisions depend on such measurements (e.g. regulatory, trade, production) often they can only be carried out in testing laboratories which must be accredited (according to the international standard ISO/IEC17025) for these specific measurements. The intention of such accreditation by a third party is to assurethe customer that the laboratory which performs the measurement is competent. Surprisingly, higher education curricula rarely teach the competences needed in this context. The Measurement Science in Chemistry International Master Programme was created exactly for this purpose in 2008. It has run an annual international summer school, which is a pivotal learning activity for the consortium.

In a recent article in this journal, R. Salzer questioned whether academic study programmes sufficiently follow the rapid changes in society and whether they sufficiently prepare young people for new challenges so as to increase their

Philip D. P. Taylor

philip.taylor@ec.europa.eu

1 European Commission JRC, Retieseweg, 2440 Geel, Belgium

2 Adam Mickiewicz University, Grunwaldzka 6, 60-780 Poznań, Poland

3 Department of Chemistry and Biochemistry, DQB- FCUL, University of Lisbon, Campo Grande, C8, 1749-016 Lisboa, Portugal

4 Laboratory for Analytical Chemistry, University of Maribor, Smetanova 17, 2000 Maribor, Slovenia

5 University of Warsaw, Pasteura 1, 02-093 Warszawa, Poland employability [1]. He argued that, although a strong foundation in the fundamentals and a diverse knowledge of cuttingedge research are important, students can further differentiate themselves by developing their non-technical skills. Interdisciplinary knowledge and transferable skills seem to be very important in the employment market [2-4].

Have such concerns been taken into account in the process of changing university curricula? The need for change in higher education structures in the face of globalisation was addressed in the Bologna Process, dealing with issues such as public responsibility, governance and social dimension, promoting student mobility and attracting non-Europeans to study and/or work in Europe. Some might argue that the emphasis of this reform was rather on administrative reorganisation than on modernising learning outcomes or adapting them to external requirements.

As for changes in external requirements, what have been the major changes in the world of analytical sciences and analytical laboratories during recent decades? Apart from the rapid technological developments, the requirements of quality assurance of analytical results and laboratory accreditation (according to ISO/IEC-17025) have had a very influential role all across the

6 Université Claude Bernard Lyon 1, Bâtiment Berthollet, 22 Avenue Gaston Berger, 69622 Villeurbanne cedex, France

7 Maria Curie-Skłodowska University, Pl. M.C.Skłodowskiej 3, 20-031 Lublin, Poland

8 Vrije Universiteit Brussel, Pleinlaan 2, 1050 Brussel, Belgium

9 University of Tartu, Ravila 14a, Tartu 50411, Estonia

10 EucheMS, Troonstraat 62, 1000 Brussels, Belgium

11 South-West University 'Neofit-Rilski', 66 Ivan Michailov st., 2700 Blagoevgrad, Bulgaria

12 Department of Chemistry, University of Oulu, Pentti Kaiterankatu 1, 90014 Oulun yliopisto, Finland 
world. The importance of accreditation has risen to the level that without it laboratories can often go out of business. Have university curricula adapted themselves correspondingly to better prepare students for the job market where analytical chemists find employment? By and large, this has rarely happened. Students are often taught analytical techniques in their science or engineering education from the perspective of continuing a career in research, rarely addressing the knowledge and skills required in the context of an accredited laboratory. Thus it seems that genuine market needs are not so easily taken on board when changes to educational curricula are considered, although a qualifications framework and employability are intimately linked [5], as depicted in Fig. 1 taken from this reference.

This paper describes a summer school organised in the context of an International Master Programme (Measurement Science in Chemistry, MSC) currently involving nine partner universities, which was specifically set up in 2007 to address a qualification framework required by many employers, namely to have graduates with knowledge and competences required to work in an accredited laboratory. The development of this programme [6, 7] started in 2005, when the European Commission Joint Research Centre assembled a group of analytical chemistry lecturers in a workshop in Rogaška Slatina, Slovenia [8]. They addressed the need for introducing curriculum changes as described above. The findings were supported by many European stakeholders in a Rogaška Declaration [9]. In a follow-up meeting in Wieliczka in 2007, a consortium was created which set up a programme, later submitted to the Label Committee of the European Chemistry Thematic Network [10]. It is this programme which received its first Euromaster quality label in 2008 later renewed in 2013. The requirements for the Euromaster label are that Euromaster graduates will develop learning skills which will allow them to continue to study in a manner which may be largely selfdirected or autonomous, and to take responsibility for their own professional development.

Fig. 1 Learning outcomes in higher education and employability [5]
This master programme attracts approximately the best $10 \%$ of the master students of each of the consortium partners. For organisational and cost reasons, these students follow the bulk of their curriculum at their home university. However, these selected students then participate in a crucially important learning activity in the context of the MSC master programme, i.e. the international summer school. To the best of the authors' knowledge, it is currently the only summer school worldwide which enables students to develop expertise and skills directly related to working in an accredited laboratory. Organising the first summer school was critical in demonstrating its feasibility. It was held in Celje (Slovenia) in 2008 [11]. To demonstrate its European aspect as well as to spread the challenge of organisation across the partners, the school was subsequently held in Blagoevgrad (2009), Lepanina (2010), Poznań (2011), Fátima (2012), Lyon (2013) and Casablanca (2014).

\section{Desired competences}

A classic format of a summer school is to invite researchers in a particular research subject domain who then lecture on their specific research. The methodology for this school is somewhat different. On the one hand, it is centred on what the student is to learn in the area of laboratory accreditation. On the other hand, the proportion of active learning in the MSC summer school is much higher than in many other summer schools. Clear learning outcomes have been described for each set of skills and abilities (Table 1). They are taught by teachers proven to have the required expertise.

\section{Programme}

A suitable programme was developed with a variety of teaching and learning activities as well as matching assessment. A

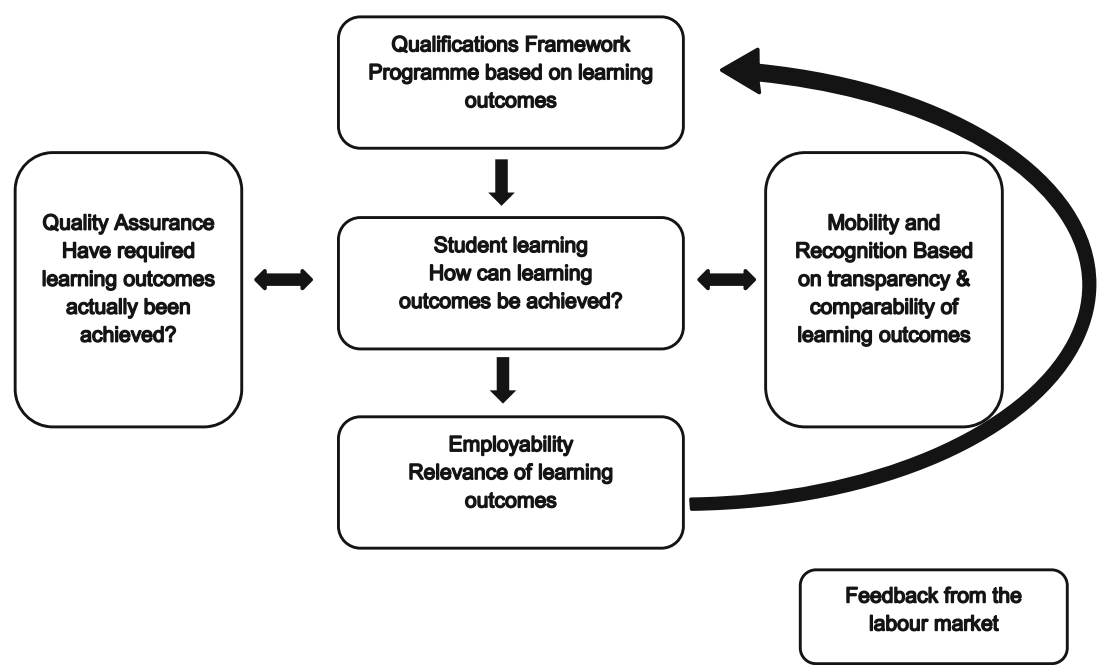


Table 1 Learning outcomes for the Euromaster Measurement Science in Chemistry Summer School

Knowledge and understanding

Students should be able to demonstrate:

- An adequate knowledge and understanding of the principles of metrological traceability, comparability, compatibility, measurement procedure, validation, bias, repeatability, withinlaboratory reproducibility (intermediate precision), uncertainty, internal and external quality control

- An understanding of what is a laboratory quality system based on the ISO/IEC-17025 standard, including the process of auditing and laboratory accreditation

- An awareness of the relevance of measurement science in a wider multidisciplinary context

Intellectual abilities

Students should be able to:

- Solve unfamiliar measurement problems which are incompletely defined and have competing specifications

- Apply their knowledge and understanding to design solutions to unfamiliar problems

- Use creativity to develop new and original ideas and methods

- Display professional judgement, when faced with technical uncertainty and incomplete information, to tackle complex problems

Practical skills

Students should be able to:

- Estimate bias, precision, repeatability and uncertainty of their measurements (using the model equation approach and nonmodelling approaches)

- Identify the customer requirements via a dialogue with the customer

- Subsequently perform validation of a measurement procedure, documented in a validation report

- Document their measurement results in a report

- Properly report a result (rounding, indicating uncertainty and traceability statement)

- Defend their measurement procedure and their results in a public defence

- Formulate questions so as to perform a laboratory audit

- Master the basic laboratory skills of diluting, such as preparing calibration curves and identify, locate and acquire required data

- Critically evaluate measurement data and draw appropriate conclusions

- Integrate knowledge and handle complexity

- Demonstrate a comprehensive understanding of applicable approaches, techniques and methods, and of their limitations

Transferable skills

Students should be able to:

- Effectively communicate and work in an international team, including management of conflicts and multi-cultural interactions

- Manage their time, prioritise work and meet project deadlines

- Properly design, plan and manage their laboratory project work

- Express themselves in English, both orally as well as for report writing

brief description can be found in Table 2. Timing of the various modules is important, as the aim is always that students can quickly apply what they learned from the lectures in their subsequent practical laboratory work. Specific learning outcomes are defined for each separate module in the programme and a detailed day-by-day script helps teachers to organise the time. The detailed scenario is also essential for dividing the teaching and laboratory supervision responsibilities as different teachers are involved at different moments during the school. Continuity across the period of the school is essential which means that information on students and their activities needs to be monitored and transferred.

The summer school makes use of a mixture of different teaching methods, including lectures, active learning, project work, case studies and assignments. There is quite some emphasis on problem-based learning (PBL), which has been recognised as being a powerful means of improving the transfer of knowledge in education, particularly to current generations who may tend to have shorter attention spans. Robinson [12] explained that this method addresses the challenge of motivating students to perform at their highest level while engaging them in the process of learning. They perform a complex, authentic task, students make their own choices about the pathway for completing the project, and collaboration and teamwork are used to make important decisions in moving the project forward. PBL represents a paradigm shift from traditional teaching and learning philosophy and the constructs for teaching PBL are very different from traditional classroom/lecture teaching. They follow the saying of the ancient Chinese philosopher Xun Zhi: "Tell me, I'll forget. Show me, I'll remember. Involve me, I'll understand."

The backbone of the 2-week summer school is a very realistic game which runs over an 11-day period. At the start of the game, students are divided into balanced teams (typically ten teams of four people, balanced in gender, language, culture) and are asked to create an independent analytical laboratory, with its management structure and shared responsibilities (this structure is relevant in the context of the ISO/IEC-17025 standard). Each team also creates a company logo and presents the company to the customer, other students and teachers. Each team carries out a specific service analysis for a customer (the lab facility is provided). They need to work as a laboratory accredited to perform this analysis. By playing this game, students learn the essentials of the international standard ISO/IEC-17025 on quality management in a laboratory. Day by day, throughout the game, they come into close contact in a practical way with many of the key issues raised in the standard. The students realise that, in real life, a laboratory cannot be accredited in a 2-week time span, but the most important challenges involved in working in an accredited laboratory are explained during the school. During this period, they are asked to solve a problem raised by the customer through the analysis of an unknown sample and they are expected to interpret the analytical information.

The laboratory work, which starts on day 2 , at the venue of the summer school is chosen in such a way that it can be performed with simple instrumental means (e.g. typically UV-Vis spectroscopy). Setting up laboratory facilities in a non-laboratory environment can be quite a challenge asking for improvisation, efficient coordination and prompt action. As laboratory work takes up quite some time, on such 
Table 2 Typical programme for the Euromaster Measurement Science in Chemistry Summer School

\begin{tabular}{|c|c|c|}
\hline Day & Activity & Objective \\
\hline & $\begin{array}{l}\text { - Laboratory analytical work: the laboratory is made available from day } \\
2 \text { to day } 9 \text { for } 1.5 \mathrm{~h} \text { per day and per team }\end{array}$ & - Perform analysis for client \\
\hline 1 & - Arrival and ice breaker reception & - Getting to know each other \\
\hline 2 & $\begin{array}{l}\text { - Opening and general introduction to the summer school. Explanation of the } \\
\text { accredited laboratory game } \\
\text { - Assignment of students to various teams } \\
\text { - Communication exercise: client-laboratory interaction (interactive lecture) } \\
\text { - Teams go outdoors to sample (e.g. water samples) and perform a so-called } \\
\text { simple analysis (pH, conductivity etc.) with a variety of hand-held instru- } \\
\text { ments }\end{array}$ & $\begin{array}{l}\text { - Explaining methodology, expectations, assessment, } \\
\text { homework } \\
\text { - Creation of teams } \\
\text { - Initiate interaction of student labs with "the client" } \\
\text { - Team-building activity }\end{array}$ \\
\hline 3 & $\begin{array}{l}\text { - Students review their field analysis data of day } 2 \text { in a group session } \\
\text { - Quality in the laboratory: ISO/IEC-17025, accreditation (lecture) }\end{array}$ & $\begin{array}{l}\text { - Create awareness that measurement is not trivial } \\
\text { - Basics on ISO/IEC-17025 and expectations from students re- } \\
\text { garding laboratory work (record keeping, validation, } \\
\text { reporting etc.) }\end{array}$ \\
\hline 4 & $\begin{array}{l}\text { - Basic statistics (lecture) and review basic laboratory skills (practical session) } \\
\text { - Traceability and use of CRM, linked to field analysis where possible } \\
\text { (interactive lecture) }\end{array}$ & $\begin{array}{l}\text { - Make sure all are on same level } \\
\text { - Create adequate understanding in these areas }\end{array}$ \\
\hline 5 & $\begin{array}{l}\text { - Calibration, linked to field analysis where possible (interactive lecture) } \\
\text { - Validation (lecture and case studies) }\end{array}$ & - Create adequate understanding in these areas \\
\hline 6 & $\begin{array}{l}\text { - Measurement uncertainty [Part I: modelling approach; lecture and case studies] } \\
\text { - Measurement uncertainty [Part II: Nordtest approach; lecture and case studies] }\end{array}$ & - Create adequate understanding in these areas \\
\hline 7 & $\begin{array}{l}\text { - Internal and external quality control, linking to field analysis where possible } \\
\text { (interactive lecture) } \\
\text { - Summer school outing }\end{array}$ & - Create adequate understanding in these areas \\
\hline 9 & $\begin{array}{l}\text { - Skills to review and write a scientific paper (case studies) } \\
\text { - Auditing skills and preparation of auditing workshop (lecture) }\end{array}$ & $\begin{array}{l}\text { - Improve English-language written communication skills } \\
\text { - Explaining the basics of laboratory auditing }\end{array}$ \\
\hline 10 & $\begin{array}{l}\text { - Practical workshop on assessment and auditing skills (students interviewing } \\
\text { teachers who play the role of laboratory staff being audited) }\end{array}$ & $\begin{array}{l}\text { - Allow students to practice skills to ask relevant questions } \\
\text { in a laboratory audit }\end{array}$ \\
\hline 11 & $\begin{array}{l}\text { - Guest lecture on a research topic with special emphasis on quality of data } \\
\text { - Students visit a real accredited laboratory and carry out an audit }\end{array}$ & $\begin{array}{l}\text { - Broaden students' horizons } \\
\text { - Enable students to witness practice in a real accredited } \\
\text { laboratory }\end{array}$ \\
\hline 12 & $\begin{array}{l}\text { - Preparation for assessment and finalisation of measurement report for each } \\
\text { team (submission of results) } \\
\text { - Assessment (written exam) }\end{array}$ & $\begin{array}{l}\text { - Train planning and prioritisation skills } \\
\text { - Evaluate the knowledge in the key areas of metrology in } \\
\text { chemistry }\end{array}$ \\
\hline 13 & $\begin{array}{l}\text { - Each team presents their work to a jury } \\
\text { - Feedback from inter-laboratory comparison } \\
\text { - Feedback from assessment results }\end{array}$ & $\begin{array}{l}\text { - Practice presentation and discussion skills } \\
\text { - Review and discuss learning outcome of the inter-laboratory } \\
\text { comparison } \\
\text { - Review the assessment }\end{array}$ \\
\hline 14 & - Dep & \\
\hline
\end{tabular}

occasions sufficient labware, (portable) instruments and chemicals are brought in. This way, students do not need to be transported to the laboratory and teams have sufficient time to access the laboratory. Importantly, also here, student teams need to plan their work and need to book time to access this laboratory (the number of instruments and other lab items is limited and is smaller than the number of teams).

Contrary to classic laboratory activity, no experimental protocol is given to the students on what and how to analyse so as to solve the customer request. The protocol developed by students is assessed by teachers and, if needed, corrections are introduced before allowing the group to proceed with their experimental work. This intermediate assessment ensures that students will have a better chance of completing their task.
Teachers present during laboratory activities only answer closed questions related to this laboratory work, to encourage students to properly formulate questions.

On day 2 of the school, the newly formed teams also get an outdoor challenge, typically an activity involving sampling and analysis (e.g. different teams sample water at different locations; coordinates are given; teams need to find their way independently to the various locations). It is a first test of internal team communication. Each team then performs a measurement with mobile equipment ( $\mathrm{pH}$, conductivity, salinity, dissolved oxygen concentration etc.) on their sample and results are critically assessed the following day. The aim is to create awareness of the fact that measurement is not trivial. Issues on validation, traceability, calibration, uncertainty etc. 
surface, are noted and where possible these experiments are used in subsequent lectures.

After a brief introduction lecture on the ISO/IEC-17025 standard and an explanation of the game itself (the actors involved, what is expected from them, laboratory facility, access to the laboratory etc.) the teams try to find out exactly what the customer wants and the specific requirements for the measurements to be performed. Each team books time for such a meeting with the customer. This customer-laboratory interaction is a cornerstone of the ISO/IEC-17025 standard and the translation of customer requirements into measurement requirements is essential to be able to carry out the method validation. At the end of day 4, students must have clarified customer requirements (within laboratory reproducibility, uncertainty, timing etc.).

During days 4-7, several lectures explain key metrological issues, e.g. measurement traceability, use of reference materials, validation, uncertainty, compliance, internal and external quality control and inter-laboratory comparisons.

In the second week, as students make progress in their own laboratory work, more in-depth information on the ISO/IEC17025 standard is given. A lecture on the topic is followed by a role play to teach students what a laboratory audit is in the context of accreditation. In this role play, each student team gets a specific paragraph of the standard to audit. Before students visit a real accredited laboratory, they practice with the teachers. Teachers play the role of laboratory personnel (owner of the company, laboratory responsible, quality manager, analyst etc.) and students ask their prepared questions based on the quality manual of the laboratory made available to them. In this game, various scenarios have been developed for the teachers to play, based on realistic situations. Following this exercise, on day 11, the students subsequently perform an audit of a real accredited laboratory. After the visit, each team produces and submits a laboratory audit report.

During the school, students practice their Englishlanguage skills intensively. Interacting both professionally and socially over a 2 -week period is an intensive learning exercise in communication. During day 9, time is also devoted to written English skills and to the process of writing and reviewing scientific papers. The Euromaster MSC curriculum requires that each student submits a brief scientific paper in English on the research carried out during their master's thesis. The articles of their predecessors are made anonymous and used as teaching material. Each team gets a paper and needs to produce a review report. This report is presented in plenum to teachers who play the role of authors.

By the end of day 12, the teams need to have finalised their practical laboratory work and prepared their report. This report should include the answer to the customer's question, typically the compliance or non-compliance of an item with a specification, and a detailed measurement report. The deadline for this final report is set in a strict way, as explained abundantly at the start of the school. In this way, their skills for time management and prioritisation are practised. The proficiency of groups to produce valid analytical information is assessed by comparing estimated and reference values of the customer's sample, both reported with uncertainty, by calculating z-scores, En-scores and checking metrological compatibility. Any deviation observed in reported results is critically reviewed.

\section{Assessment}

The assessment for the summer school is explained to the students at the start of the school. In total, $65 \%$ of the score is related to the analytical game. The $65 \%$ is split into two parts, i.e. one part $(40 \%)$ is attributed to post summer school assignments (i.e. report on the laboratory audit, an assignment on measurement uncertainty, one on validation and one assignment on creating exam questions) the other (25\%) is attributed to the team performance during the school (i.e. performance in the laboratory, quality of the analytical report, quality of the public defence). There is also a final individual examination, which carries the remaining $35 \%$ of the score. Students get half a day to prepare for the exam.

On the final day of the summer school the students' companies present their results, in plenum, in front of a jury panel, which allows extensive questioning. The results for the unknown sample of all student companies are displayed against the reference and in this way they have also participated in an inter-laboratory comparison.

\section{Resources}

The Euromaster MSC differs from consortia which depend on large but time-limited (e.g. 3 years) funding schemes (e.g. Erasmus) and its funding has been of a more hybrid nature. On the other hand, less administrative effort was needed for administrative project management. The partners carry part of the cost as well as the students. Sponsors are also attracted and sometimes smaller EU funding sources have been used (e.g. Erasmus Intensive Programme and Erasmus Bilateral). Typically, about five places are also made available to external (i.e. non-consortium) students to contribute to the cost of the school.

\section{Results}

In total, some 280 students participated in the seven summer schools. Two surveys amongst Euromaster MSC alumni 
(2012 and 2014) have shown that their rate of employment is very high (more than $95 \%$ are employed 6 months after graduating). From their testimonies, one can conclude that their experience in their master programme and specifically in the summer school profoundly and positively changed their professional profile. Many testified that, during their recruitment interview, the main topic of discussion was actually their participation in the summer school.

Although the aim of the summer school has never been to modify curricula of the individual partners, it can safely be said that indirectly the intensive interaction of lecturers before and during the summer school has influenced learning outcomes and inspired changes in the curricula. As the consortium activities were not linked to a time-limited project where concrete deliverables are set by certain dates, changes might have been slower. On the other hand, the time horizon to introduce change was longer, and possibly there was greater focus on the learning outcomes of the programme.

\section{Conclusion and outlook}

The Euromaster MSC curriculum has fully addressed the need to teach master students early on the necessary knowledge and skills regarding quality related to testing laboratories, as formulated in ISO/IEC-17025. It is often said that interdisciplinary education and research have to play a larger role in higher education curricula. The Euromaster MSC curriculum has fully addressed this challenge and embraced problem-based learning to achieve this, particularly via its summer school:

- Core analytical skills are taught which are directly linked to quality of analytical data as addressed in the ISO/IEC17025 standard (e.g. traceability, validation, uncertainty). It is key to expose students at an early stage in their education to ISO standards regarding good laboratory practice.

- Enhancement of transferable or so-called soft skills as well as entrepreneurial skills is an intrinsic part of the training programme, such as the skills needed for planning, time management, (intercultural) communication, team play and leadership.

Since 2008, the community of alumni has grown to several hundreds from some 20 different countries. They have gradually become involved in the running of the summer school, particularly as many have taken up careers in research and/or companies. They are eager to contribute to the summer school in various more active ways, by sharing their experience and expertise. The intention is to develop this dimension of the school in more depth in the future, so as to create an active community. It is highly likely that the learning objectives of future schools will evolve as a consequence. In particular the possibility to increase the development of entrepreneurial skills during the school by involving alumni who work in companies will be considered.

The upcoming summer schools for 2015 (Puławy, Poland) and 2016 (Malle, Belgium) have been planned. Increasing interest from non-consortium university students and lecturers poses a new challenge. As it is physically not possible to run a school for double the number of students (and thus increase the consortium), other organisational schemes are being explored. The detailed summer school scenario is expected to play an essential role in this. This will also require identifying and training new teachers for the school.

Summarising, the Euromaster MSC summer schoolwhich is still the only summer school worldwide which teaches students about ISO/IEC-17025 laboratory accreditation - has proven to be a robust initiative to bring university curricula in analytical sciences closer to the competences required by employers, thus improving employability of students.

Acknowledgment The authors would like to thank Reiner Salzer for his support in creating and sustaining this international consortium and Sylvie Childs and Vaidotas Gegevicius for their efforts in making this summer school a success.

\section{References}

1. Salzer R (2014) Anal Bioanal Chem 406:3251-3255

2. European Parliament Research Service (2014) http://epthinktank. eu/2014/03/26/are-universities-fostering-graduate-employability/. Accessed Feb 2015

3. European Commission/EACEA/Eurydice (2014) Modernisation of higher education in Europe 2014: access, retention and employability. Eurydice Report. https://www.education.ie/en/Publications/ Education-Reports/Modernisation-of-Higher-Education-inEurope--Access-Retention-and-Employability-2014-.pdf. doi:10. $2797 / 72146$

4. European Chemical Industry Council (CEFIC) (2011) Skills for innovation in the European chemical industry. http://www.cefic. org/Documents/PolicyCentre/Skills-for-Innovation-in-theEuropean-Chemical-Industry.pdf. Accessed Feb 2015

5. European Chemistry and Chemical Engineering Education Network (2012) Implementing outcomes-based education in chemistry and chemical engineering, work package 15 . www.ec2e2n. net. Accessed Feb 2015

6. Leito I, Kruve A (2010) Anal Bioanal Chem 397:1635-1637

7. Euromaster Measurement Science in Chemistry (2015) http://www. msc-euromaster.eu/. Accessed Feb 2015

8. Prohaska T, Bulska E, Duta S, Leito I, Magnusson B, Majcen N, Prichard E, Robouch P, Suchanek M, Taylor P, Vassileva E, Wegscheider W (2006) Anal Bioanal Chem 385:1031-1032

9. Rogaška Declaration (2006) GE/R/IM/35/06, European Commission JRC, 2006

10. Chemistry Quality Eurolabels ${ }^{\circledR}$ (2015) http://ectn-assoc.cpe.fr/ chemistry-eurolabels/default.htm. Accessed Feb 2015 
11. Leito I (2008) Measurement science in Chemistry Summer School 2008. Accred Qual Assur 13:675

12. Robinson JK (2013) Anal Bioanal Chem 405:7-13

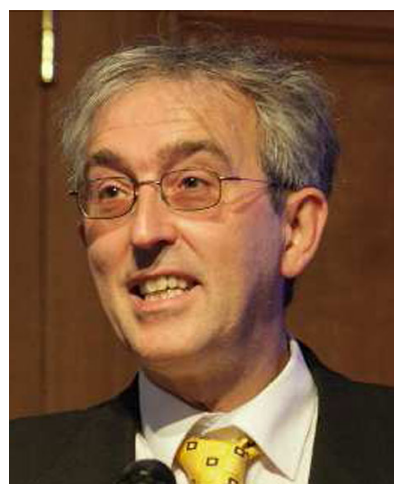

Philip Taylor works for the European Commission Joint Research Centre. His current research interests lie in measurement and testing linked to aviation security and detection of CBRNE security threats (Chemical, Biological, Radioactive, Nuclear and Explosives). These activities support the EU security policy. Furthermore, he has been involved in laboratory capacity building projects in the context of EU enlargement and the European Neighbourhood policy.

There has, however, been one recurring theme which links up all these areas: how to ensure quality of measurement data. This is very important in the context of ISO/IEC-17025 laboratory accreditation and the European Regulatory context.

For this reason, in 2001 he created a European Training platform for metrology in chemistry (TrainMiC®) involving experts from all across the EU. This was later followed by a teaching initiative, the Euromaster Measurement Science in Chemistry International Master Programme, which is described at length in this paper.

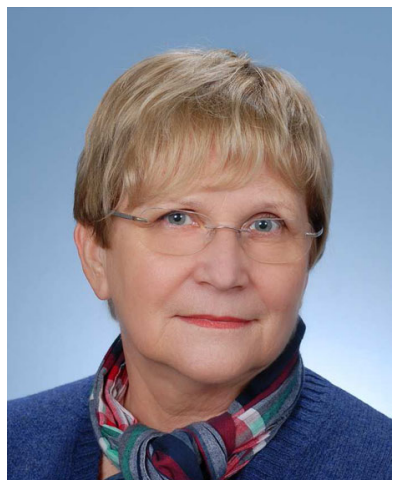

Danuta Barałkiewicz teaches analytical chemistry at the Adam Mickiewicz University in Poznan and is the Head of the Department for Trace Elements Analysis by Spectroscopic Methods. She is an elected member of the Committee of Analytical Chemistry of the Polish Academy of Science. In her research, she applies advanced analytical techniques such as mass spectrometry with inorganic and organic ionisation. She cooperates with representatives of various disciplines who are interested in environment, food, biology and medicine. She has been active in introducing metrology and chemometrics in analytical chemistry.

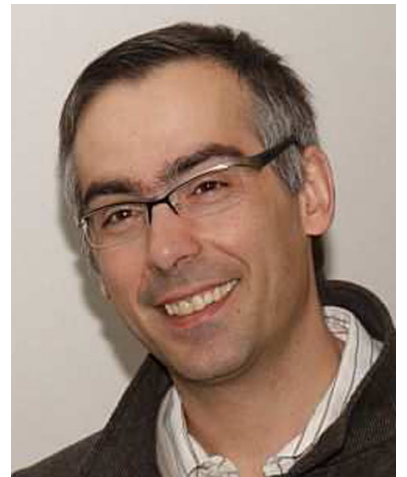

Ricardo J. N. Bettencourt da Silva is a Researcher of the Centro de Química Estrutural of the University of Lisbon and has been teaching analytical chemistry and metrology in chemistry at the Faculty of Sciences of the University of Lisbon. The main topics of his research are metrology and examinology in chemistry, the sciences of quantitative and qualitative evaluations in chemistry respectively. For both kind of evaluations, detailed measurement and examination models are developed so as to extract reliable and more complete information from complex systems. The developed tools have been used to study relevant environmental, food and forensic systems. He is active in teaching and developing these topics in national and international teaching programs, working groups and forums.

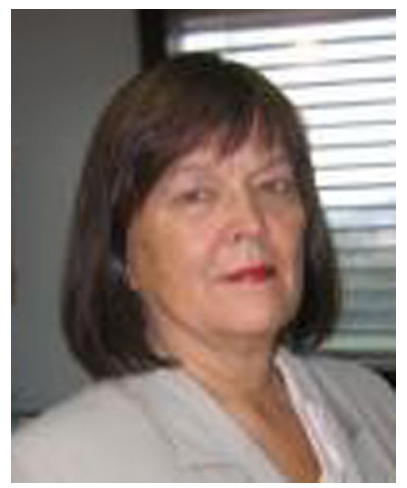

Darinka Brodnjak Vončina teaches analytical chemistry at the University Maribor. She has a research interest in metrology in chemistry and chemometrics. She is President of the Maribor section of the Slovenian Chemical Society.

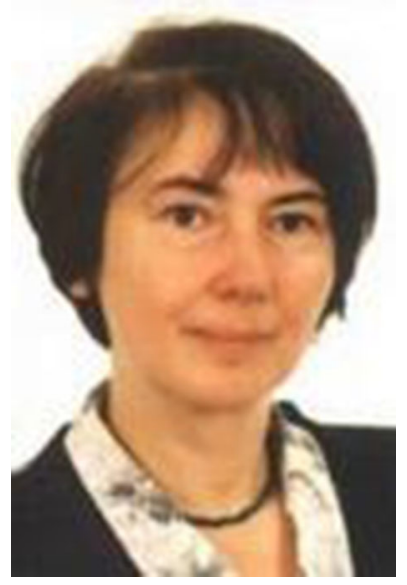

Ewa Bulska lectures in analytical chemistry and is Director of the Biological and Chemical Research Center at the University of Warsaw and Head of the Unit of Theoretical Aspects of Analytical Chemistry at the Faculty of Chemistry. She is an elected member of the Committee of Analytical Chemistry of the Polish Academy of Sciences and she acts as Head of the Atomic Spectrometry Working Group and is also a member of the editorial board of the TrainMiC $\AA$ programme and team leader of the PL TrainMiC ${ }^{\circledR}$ team. She serves as an assessor for ISO/IEC-17025 for several accreditations bodies, namely in Poland, Bulgaria, Croatia and Turkey. She is also an expert of WADA in respect to quality systems in anti-doping laboratories.

Her research interests are analytical chemistry; metrology in chemistry; inorganic and bioinorganic trace analysis; environmental, industrial, clinical and food samples; archaeometry. 


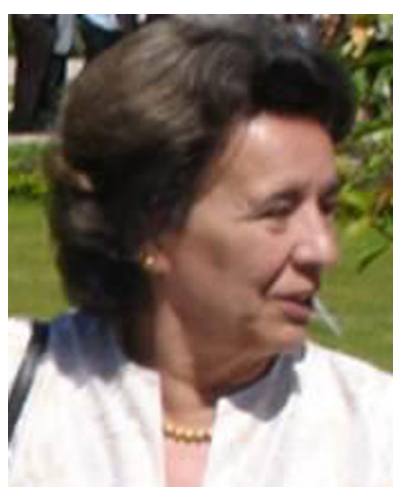

Maria Filomena Gomes Ferreira Crujo Camões is Professora Associada com Agregação at the University of Lisbon, Portugal. In this capacity she is also coordinator of the Research Group on Analytical and E n v i r o n m e n t a 1 Chemistry-CQE@FCUL. Among the various national and international functions she has held, she is presently coordinator of the EuroMaster ${ }^{\circledR}$ on Measurement Science in Chemistry, member of the TrainMiC ${ }^{\circledR}$ national team and advisory board). From 1996-2010 she was advisor to the Minister of Education on National Examinations (chemistry and environmental sciences). Among other events, she was in charge of the organization of the 37th IUPAC General Assembly (1993) and chaired the organization of EUROANALYSIS XI (2000).

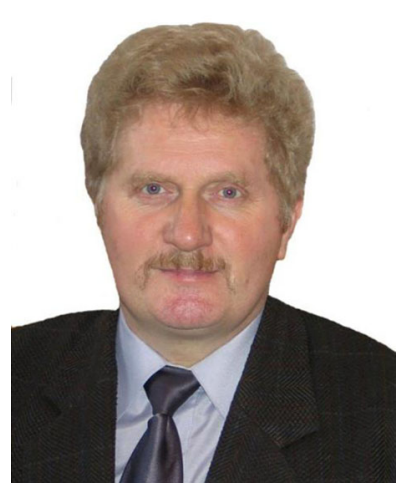

Ryszard Dobrowolski graduated in 1977 from the Faculty of Chemistry, Maria CurieSkłodowska University, Lublin (Poland). He was initially employed in the Central Laboratory of Special Equipments as an assistant. He received his Ph.D. in 1988 and his habilitation in 2003. Since 2005 and 2014 respectively, he has held the position of assistant and full professor at the same university. His research areas include: electrothermal atomic absorption spectrometry, environmental trace element analysis, synthesis and characterissation of sorbents for the separation of selected trace metal ions. The focus of his teaching is on trace metals analysis, and the metrological and statistical aspects of measurements. Since 2004 he has been involved in the international AcadeMiC and TrainMiC educational projects.

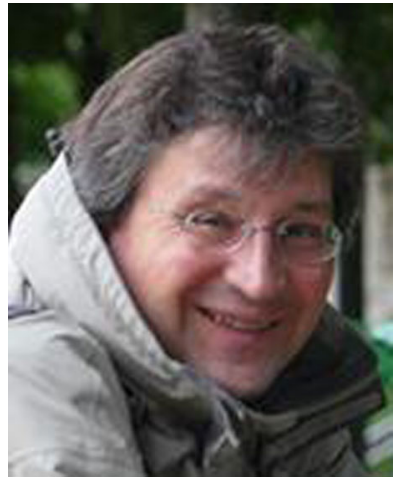

Marc Elskens lectures in chemometrics at the Vrije Universiteit Brussel (VUB) and he has expertise in the domain of transformations, transport and fate of chemicals in water; water resources and quality; stable isotope modelling in aquatic systems. His research approach is based on the development and application of chemometrics to environmental analysis and data mining. In the past few years he has been involved in the development of bioanalytical methods for the assessment of persistent organic pollutants in several matrices including food contact materials, human fluids and environmental samples.

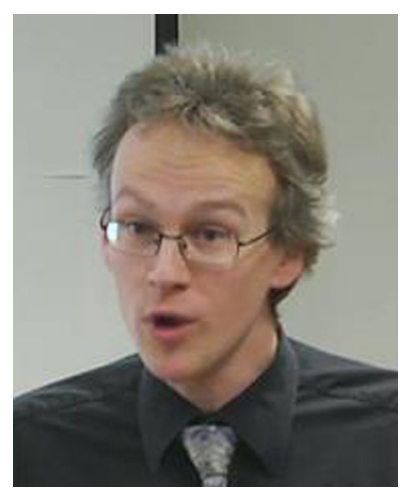

Ivo Leito lectures in analytical chemistry at the University of Tartu. His research directions are on the borderline of analytical chemistry with other disciplines: chemistry of superacids and superbases; metrology in chemistry (MiC); liquid chromatography and mass spectrometry; sensors and their metrological characterization; applications of instrumental methods in analysis of historical objects.

He has been involved in setting up several international MiCrelated educational activities.

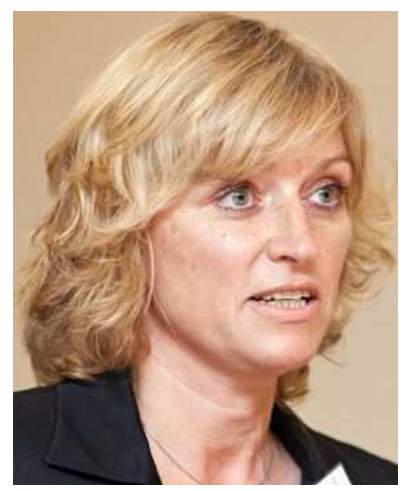

Nineta Hrastelj Majcen works as the general secretary of the European Association for Chemical and Molecular Sciences (EuCheMS). She studied at the University of Ljubljana, Slovenia. Her research topics span across analytical chemistry, chemometrics and metrology. In recent years, her expert work has mostly been about quality of analytical measurements, where, amongst others, she has been chairing the TrainMiC editorial board and is a founding member of both TrainMiC ${ }^{\circledR}$ and the Measurement Science in Chemistry (previously AcadeMiC) programme of the European Commission JRC.

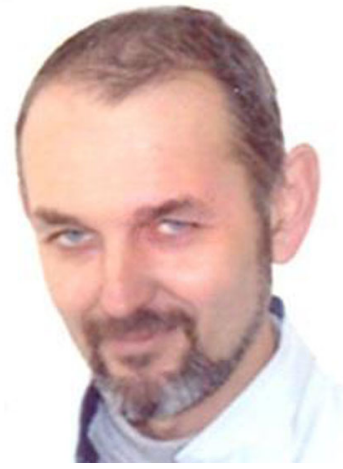

Petko Mandjukov lectures in analytical chemistry at the SouthWest University-Blagoevgrad. $\mathrm{He}$ is an expert at the International Atomic Energy Agency (IAEA). His research interests are in the field of metrology in chemistry, chemometrics, statistics, analytical chemistry, atomic spectroscopy and environmental monitoring. 

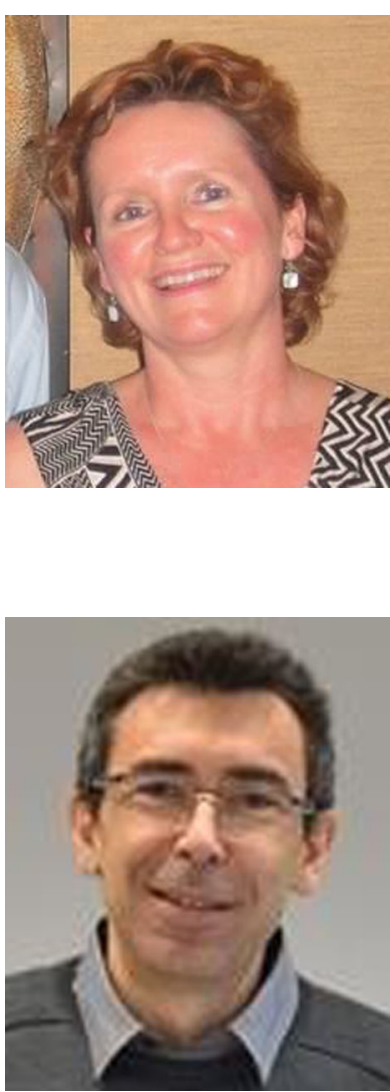

of the French Society of Chemistry.
Josephine McCourt works for the European Commission Joint Research Centre. As an analytical chemist, she has been involved in applied research in both environmental and food areas. Lately, she has been involved in capacity building and training in support of EU Neighbourhood countries via the TrainMic ${ }^{\circledR}$ programme. She is also involved in capacity building activities in the area of CBRNE (Chemical, Biological, Radioactive, Nuclear and Explosives) risk mitigation.

Jérôme Randon is Professor of Analytical Chemistry at the Analytical Science Institute at the University of Lyon. He is the team leader of the research group in separation science (monolithic columns, lab on chip, LCxLC). $\mathrm{He}$ is also deeply involved in education in analytical chemistry: former director of PRACTICE, director of the master degree in analytical sciences (http://masteranalyse-controle.univ-lyon 1.fr) and member of the board of the Teaching and Education Division

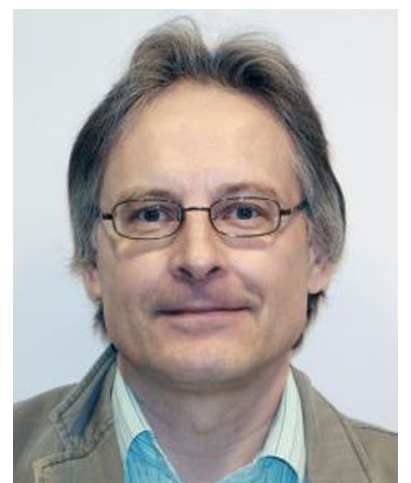

Paavo Perämäki has been lecturing chemistry at Oulu University since 1993. His primary research areas include sample preparation and pretreatment methods for trace element analysis and method development for trace and ultratrace analysis utilizing atomic spectrometric techniques (ETAAS, ICP-OES) and ICPMS. His research focuses on chemometric tools, especially statistical experimental design. 